\title{
Favorable late survival after aortic surgery under straight deep hypothermic circulatory arrest
}

\author{
Anneke Damberg, MD, ${ }^{a}$ Davide Carino, MD, ${ }^{a}$ Paris Charilaou, MD, ${ }^{\mathrm{a}}$ Sven Peterss, MD,,${ }^{\mathrm{a}, \mathrm{b}}$ \\ Maryann Tranquilli, RN, ${ }^{\mathrm{a}}$ Bulat A. Ziganshin, MD, PhD, ${ }^{\mathrm{a}, \mathrm{c}}$ John A. Rizzo, PhD, ${ }^{\mathrm{a}, \mathrm{d}, \mathrm{e}}$ and \\ John A. Elefteriades, $\mathrm{MD}^{\mathrm{a}}$
}

\section{ABSTRACT}

Background: Surgical and cerebral protection strategies in aortic arch surgery remain under debate. Perioperative results using deep hypothermic circulatory arrest (DHCA) have been associated with favorable short-term mortality and stroke rates. The present study focuses on late survival in patients undergoing aortic surgery using DHCA.

Methods: A total of 613 patients (mean age, 63.7 years) underwent aortic surgery between January 2003 and December 2015 using DHCA, with 77.3\% undergoing hemiarch replacement and 20.4\% undergoing arch replacement, with a mean DHCA duration of $29.7 \pm 8.5$ minutes (range, 10-62 minutes). We examined follow-up extending up to a mean of $3.8 \pm 3.4$ years (range, 0-14.1 years).

Results: Operative mortality was $2.9 \%$, and the stroke rate was $2 \%$. Survival was $92.2 \%$ at 1 year and $81.5 \%$ at 5 years, significantly lower than the values in an age- and sex-matched reference population. In elective, nondissection first-time surgeries $(n=424)$, survival was similar to that of the reference group. Acute type A aortic dissection (hazard ratio $[\mathrm{HR}], 4.84 ; P=.000)$, redo (HR, 4.12; $P=.000)$, and descending aortic pathology (HR, 5.54: $P=.000)$ were independently associated with reduced 1-year survival. Beyond 1 year, age (HR, 1.07; $P=.000$ ), major complications (HR, 3.11; $P=.000)$, and atrial fibrillation (HR, 2.47; $P=.006$ ) were independently associated with poor survival. DHCA time was not significantly associated with survival in multivariable analysis.

Conclusions: Aortic surgery with DHCA can be performed with favorable late survival, with the duration of DHCA period having only a limited impact. However, these results cannot be generalized for very long durations of DHCA (>50 minutes), when perfusion methods may be preferable. In elective, nondissection first-time surgeries, a late survival comparable to that in a reference population can be achieved. Early survival is adversely affected by aortic dissection, redo status, and disease extent. (J Thorac Cardiovasc Surg 2017;154:1831-9)

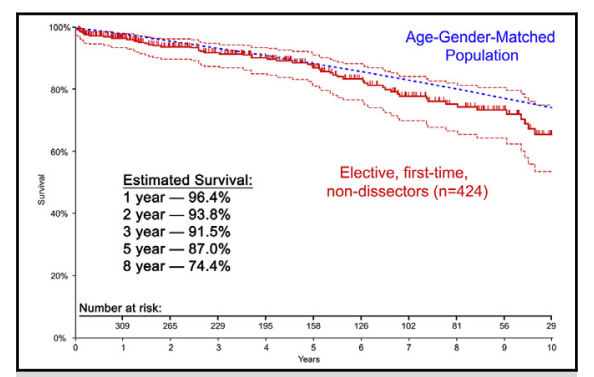

Survival of elective, first-time nondissection cases compared with the reference population $(n=424)$.

\section{Central Message}

Aortic arch surgery with deep hypothermic circulatory arrest can be performed with favorable late survival.

\section{Perspective}

Deep hypothermic circulatory arrest is a safe technique for cerebral protection in aortic arch surgery. We show that late survival is also favorable, especially in patients undergoing the procedure electively.

See Editorial Commentary page 1840.
Within the past 60 years, thoracic aortic surgery has seen a spectacular evolution. Nevertheless, uncertainties persist, mainly regarding surgical strategy, cerebral protection,

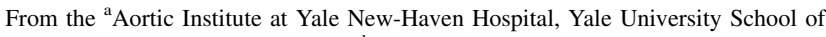
Medicine, New Haven, Conn; ${ }^{\mathrm{b}}$ Department of Cardiac Surgery, University Hospital Munich, Ludwig Maximilians University, Munich, Germany; ${ }^{c}$ Department of Surgical Diseases 2, Kazan State Medical University, Kazan, Russia; and Departments of ${ }^{\mathrm{d}}$ Economics and ${ }^{\mathrm{e}}$ Preventive Medicine, Stony Brook University, Stony Brook, NY.

Received for publication Oct 14, 2016; revisions received July 9, 2017; accepted for publication Aug 1, 2017; available ahead of print Sept 23, 2017.

Address for reprints: John A. Elefteriades, MD, Aortic Institute at Yale-New Haven Hospital, Yale University School of Medicine, Clinic Building CB317, 789 Howard Ave, New Haven, CT 06510 (E-mail: john.elefteriades@yale.edu). $0022-5223 / \$ 36.00$

Copyright (c) 2017 by The American Association for Thoracic Surgery http://dx.doi.org/10.1016/j.jtcvs.2017.08.015
}

and appropriate extent of aortic replacement. Recent studies have tended to recommend more extensive repairs and the use of moderate hypothermia with antegrade cerebral perfusion. ${ }^{1,2}$ Main concerns regarding the use of straight deep hypothermic arrest (DHCA) center around a potentially increased risk of stroke, as well as of possible subtle neurologic damage that might impair outcomes. $^{1,3,4}$ Other groups, including our own, were able

Scanning this QR code will take
you to supplemental tables for
this article.




\section{Abbreviations and Acronyms \\ ASI $=$ aortic size index \\ ATAAD $=$ acute type $\mathrm{A}$ aortic dissection \\ CI = confidence interval \\ DHCA $=$ deep hypothermic circulatory arrest \\ $\mathrm{HR}=$ hazard ratio}

to demonstrate favorable early outcomes with a duration of DHCA of up to 50 minutes. ${ }^{5}$

Expanding on our previously published positive short-term results, ${ }^{5}$ in the present study we investigated late outcomes of DHCA for aortic arch disease and identified variables associated with late survival. We aimed to determine whether DHCA itself or increased DHCA duration negatively impacts late survival.

\section{METHODS \\ Study Design}

We performed a retrospective cohort study including 613 consecutive patients undergoing aortic arch surgery using straight DHCA between January 2003 and December 2015 at the Aortic Institute at Yale-New Haven. The study was approved by the Human Investigation Committee.

\section{Patient Characteristics}

The mean age of the study group was $63.7 \pm 13.2$ years (range, 14.0-88.0 years), and $61.2 \%(\mathrm{n}=375)$ of the patients were male. The indication for surgery was aortic aneurysm in most patients $(\mathrm{n}=520$; $84.8 \%)$, but $13.1 \%(\mathrm{n}=80)$ had aortic dissection, which was acute in $36(5.9 \%)$. The remainder had various pathologies, including penetrating aortic ulcer, intramural hematoma, or free-floating atheroma. Eighty-four patients $(13.7 \%)$ underwent urgent or emergent surgery. Aortic pathology extended into the descending aorta at initial surgery in 144 patients $(23.5 \%)$.

Data on preoperative ascending aortic size was available in 473 of 478 patients undergoing elective interventions. The mean preoperative aortic size was $5.2 \pm 0.6 \mathrm{~cm}$ (range, $3.0-8.0 \mathrm{~cm}$ ). The mean aortic size index (ASI) (available in 422 patients) was $2.69 \pm 0.45 \mathrm{~cm} / \mathrm{m}^{2}$ (range, $1.58-5.02 \mathrm{~cm} / \mathrm{m}^{2}$ ). In terms of ASI risk category, 261 patients were low risk (ASI $<2.75 \mathrm{~cm} / \mathrm{m}^{2}$ ), 156 were intermediate risk, and 5 were high risk (ASI $>4.25 \mathrm{~cm} / \mathrm{m}^{2}$ ). ${ }^{6}$ Patient characteristics are summarized in Table 1.

\section{Surgical and Cerebral Protection Technique}

Our surgical strategy and cerebral protection technique have been described in detail previously. ${ }^{5}$ All procedures are performed through a median sternotomy approach. Cardiopulmonary bypass is instituted, preferably via femoral artery cannulation $(76.7 \%)$. Axillary $(14.8 \%)$, innominate artery, or direct aortic cannulation $(7.8 \%)$ is performed if the femoral artery is not safely accessible or preoperative test results suggest severe arteriosclerosis of the descending aorta, which might make retrograde perfusion unsafe. On bypass, the patient is cooled to a bladder temperature of $20^{\circ} \mathrm{C}$ (for hemiarch replacement) or $18^{\circ} \mathrm{C}$ (for arch replacement). Cooling is done gradually over at least 30 to 35 minutes, but cooling time varies widely, because cooling is usually performed during proximal reconstruction. Before and during DHCA, the patient's head is topically cooled with ice. Acid-base balance is managed using the alpha-stat method. To reduce DHCA time, the distal arch anastomosis is preferably performed proximal to the left subclavian artery, with a 2- or 3-vessel patch reimplantation of the head vessels. After DHCA, we prefer slow rewarming with a temperature gradient $<10^{\circ} \mathrm{C}$ up to $34^{\circ} \mathrm{C}$ before the patient is separated from cardiopulmonary bypass. This is warm enough to protect against arrhythmias but cool enough to provide some additional neural protection. No neuromonitoring is used.

\section{Procedural Data}

The majority of patients in the present cohort underwent hemiarch replacement $(\mathrm{n}=474 ; 77.3 \%)$. One hundred twenty-five patients $(20.4 \%)$ underwent total arch replacement, with a conventional elephant trunk used in 85 of these patients $(68.0 \%)$. In patients in whom a prompt need for descending aortic replacement is anticipated, a full elephant trunk is used, long enough to be easily accessible beyond the aortic arch during a subsequent left thoracotomy. In other patients unlikely to need an early descending intervention, a shorter "elephant trunk of convenience" is used. In these patients, we place a short invaginated elephant trunk into the descending aorta. We find that the turgor of this short trunk holds the aortic open nicely and facilitates the distal anastomosis.

The majority of patients $(n=458 ; 74.7 \%)$ underwent root-sparing aortic replacement, $149(24.3 \%)$ had root replacement, and $6(1 \%)$ had another procedure, such as patch repair, performed under DHCA. The distal arch anastomosis was sutured proximally to the left subclavian artery in most patients $(n=94 ; 75.2 \%)$. Most patients exhibited good perfusion of the left subclavian artery from flow outside the elephant trunk graft. Among those in whom the elephant trunk was occlusive, 8 patients underwent extra-anatomic subclavian artery bypass, and 2 patients required revascularization during follow-up. The head vessels were most commonly anastomosed as an island patch, and $49(39.2 \%)$ patients had individual branch grafts. In patients who required a stage 2 elephant trunk procedure for the descending aorta, the left subclavian artery was revascularized from the new descending aortic graft.

The mean duration of DHCA was $29.7 \pm 8.5$ minutes (range, 10-62 minutes). The majority of patients had a DHCA duration of $<40$ minutes $(\mathrm{n}=524 ; 85.5 \%) ; 19$ patients $(3.1 \%)$ had a DHCA duration of $>50$ minutes. The mean duration of DHCA was $26.6 \pm 5.4$ minutes (range, 10-50 minutes) for hemiarch replacements and $41.0 \pm 7.5$ minutes (range, 22-62 minutes) for total arch replacements $(P=.000)$. Surgical data are presented in Table 2.

\section{Follow-up}

Follow-up on mortality was evaluated using the United States Social Security Death Index, the EpicCare electronic medical record database (which registers deaths occurring in the state of Connecticut), online obituaries, office visits, phone calls, and e-mails. Surviving patients were censored at the date of last clinical contact at Yale-New Haven Hospital, leading to $100 \%$ complete follow-up. Our strategy for follow-up has been described and analyzed previously. ${ }^{7}$ The mean duration of clinical follow-up was $3.8 \pm 3.4$ years (range, $0-14.1$ years), and the median duration of follow-up was 2.95 years. Only the reinterventions performed at Yale-New Haven Hospital could be accounted for.

\section{Statistics}

Statistical analysis was performed using SPSS version 21 (IBM, Armonk, New York). Continuous variables are represented as mean \pm standard deviation (range), and categorical variables are presented as absolute values and percentages. Comparisons were conducted using an unpaired 2-tailed $t$ test for continuous variables and the Pearson $\chi^{2}$ test or Fisher exact test for categorical variables.

Survival was analyzed by Kaplan-Meier survival estimation, using log-rank, Tarone-Ware, and Breslow tests for comparisons. To compare the survival of the study group with that of a normal population, a reference 
TABLE 1. Demographic data, aortic pathologies, and comorbidities $(\mathrm{n}=613)$

\begin{tabular}{|c|c|}
\hline Variable & Value \\
\hline \multicolumn{2}{|l|}{ Demographic data } \\
\hline Age, $y$, mean $\pm \mathrm{SD}$ (range) & $63.7 \pm 13.2(14.0-88.0)$ \\
\hline Octogenarians, n (\%) & $75(12.3)$ \\
\hline Male sex, n (\%) & $375(61.2)$ \\
\hline \multicolumn{2}{|l|}{ Comorbidities, n (\%) } \\
\hline History of smoking & $248(40.5)$ \\
\hline $\begin{array}{l}\text { Chronic obstructive } \\
\text { pulmonary disease }\end{array}$ & $89(14.5)$ \\
\hline Arterial hypertension & $432(70.5)$ \\
\hline Diabetes mellitus & $42(6.9)$ \\
\hline $\begin{array}{l}\text { Central nervous system } \\
\text { comorbidity }\end{array}$ & $57(9.3)$ \\
\hline Chronic renal failure & $59(9.6)$ \\
\hline Dyslipidemia & $211(34.4)$ \\
\hline Atrial fibrillation & $62(10.1)$ \\
\hline Coronary artery disease & $131(21.4)$ \\
\hline Peripheral arterial disease & $22(3.6)$ \\
\hline $\begin{array}{l}\text { Previous cardiac or aortic } \\
\text { surgery, } \mathrm{n}(\%)\end{array}$ & $102(16.6)$ \\
\hline Aortic surgery & $83(81.4 \%$ of previous surgeries $)$ \\
\hline Aortic valve replacement & $57(55.9 \%$ of previous surgeries $)$ \\
\hline Ascending aortic replacement & $38(37.3 \%$ of previous surgeries $)$ \\
\hline $\begin{array}{l}\text { Partial/total aortic arch } \\
\text { replacement }\end{array}$ & $4(3.9 \%$ of previous surgeries) \\
\hline \multicolumn{2}{|l|}{ Aortic pathology, n (\%) } \\
\hline Urgent or emergent surgery & $84(13.7)$ \\
\hline Aortic aneurysm & $520(84.8)$ \\
\hline Aortic dissection & $80(13.1)$ \\
\hline Acute type A aortic dissection & $36(5.9)$ \\
\hline $\begin{array}{l}\text { Descending extension of aortic } \\
\text { disease }\end{array}$ & $143(23.3)$ \\
\hline Confirmed Marfan syndrome & $12(2.0)$ \\
\hline Positive family history & 139 (22.7) \\
\hline Bicuspid aortic valve $(n=607)$ & $176(29.0)$ \\
\hline Aortic valve stenosis & $90(14.7)$ \\
\hline Aortic valve regurgitation & $300(48.9)$ \\
\hline
\end{tabular}

$S D$, Standard deviation.

curve matched by age and sex was calculated according to life table survival data obtained from the Centers for Disease Control and Prevention for intercensal years 2006 and 2007,,$^{8,9}$ and comparisons were made using the log-rank test. The year of the life table corresponding to the mean year of surgery in the cohort was chosen for comparison. ${ }^{10}$

Variables associated with survival were identified through a Cox proportional hazards regression analysis. Results are represented as hazard ratio $(\mathrm{HR}) \pm$ standard error $(95 \%$ confidence interval $[\mathrm{CI}])$. The Cox proportional hazards assumption was assessed using a graphical approach and by creating time-by-covariate interactions for each variable. Because some important variables showed nonproportional hazards, survival analysis was divided into 2 time periods, assessing factors associated with survival for the first year and beyond the first year separately. ${ }^{11}$ For both time periods, multivariable Cox models were fitted separately. For multivariable Cox regression, univariable hazards, interactions, and the proportional hazards assumption were analyzed for variables listed in Tables E1 and E2. DHCA time was forced into the model as the main research objective. To avoid multicollinearity, variables showing strong correlation were removed from the model or grouped into a combined variable. This was especially important for variables showing a strong correlation with DHCA time. To avoid overfitting, a maximum amount of variables according to the number of outcomes was fitted into the model, and the model with the best statistical fit was chosen. Our statistical methodology has been described in a review by Rizzo et al. ${ }^{12}$

The cumulative incidence at 10 years of follow-up for the outcome of reintervention was estimated and compared between patients who had descending extension and those who did not, using a nonparametric competing-risks model (which does not assume proportional hazards), with interim death as the competing risk. The analysis was done with Stata/MP 14.2 (StataCorp, College Station, Tex), using the "stcompadj" module. Only hospital and 30-day survivors were included in analyses regarding reintervention. The level of statistical significance was set to $P<.05$.

\section{RESULTS}

\section{Early Postoperative Mortality and Morbidity}

In the study cohort, operative mortality-defined as mortality occurring within 30 days of surgery or during the postoperative hospital stay-was $2.9 \%(\mathrm{n}=18)$. Most patients who died within 30 days or in the hospital $(55.6 \% ; \mathrm{n}=10)$ were urgent or emergent cases. Among elective cases only $(\mathrm{n}=529)$, early mortality was $1.5 \%$. In elective, nondissection first-time surgeries $(n=424)$, early mortality was $1 \%$. Excluding patients age $>60$ years as well $(n=148)$, early mortality was $0 \%$. Mortality tended to be higher in patients with DHCA duration $>40$ minutes $(\mathrm{n}=4 ; 4.5 \%)$, but the difference was not significant $(P=.315)$. There was no significant difference in operative mortality between patients undergoing arch replacement and those undergoing hemiarch replacement, $(3.2 \%$ vs $2.7 \% ; P=.764)$.

Postoperative stroke-defined as stroke confirmed on cerebral imaging or a permanent neurologic deficit persisting at discharge-occurred in 12 patients $(2 \%)$. Temporary neurologic deficits were observed in 31 patients $(5.1 \%)$. As reported previously, ${ }^{5}$ stroke rates were higher in patients with a DHCA time $>50$ minutes $(10.5 \% ; P=.05)$, even though these data are based on very few patients ( 2 of 19 patients). An overview of early postoperative outcomes is provided in Table 3.

\section{Kaplan-Meier Survival Analysis and Reference Population}

Overall postoperative survival was significantly lower in our cohort compared with an age- and sex-matched reference population (standardized mortality ratio, 1.77; 95\% CI, 1.44-2.18). Estimated 1-, 5-, and 8-year survival was $92.2 \%, 81.5 \%$, and $68.6 \%$, respectively, in our patients, compared with $98.0 \%, 91.2 \%$, and $83.4 \%$ in the reference population. In patients undergoing elective first-time surgery in nondissection cases $(n=424)$, survival was no longer significantly different from that in the normal reference population (standardized mortality ratio, 1.242; 
TABLE 2. Surgical data $(n=613)$

\begin{tabular}{|c|c|}
\hline Variable & Value \\
\hline Aortic valve replacement, $\mathrm{n}(\%)$ & $338(55.1)$ \\
\hline $\begin{array}{l}\text { Biological aortic valve } \\
\text { replacement }\end{array}$ & $151(44.7)$ \\
\hline $\begin{array}{l}\text { Mechanical aortic valve } \\
\text { replacement }\end{array}$ & $187(55.3)$ \\
\hline Root replacement, n (\%) & $149(24.3)$ \\
\hline $\begin{array}{l}\text { Root-sparing aortic replacement, } \\
\text { n (\%) }\end{array}$ & $458(74.7)$ \\
\hline Hemiarch replacement, n (\%) & $474(77.3)$ \\
\hline Total arch replacement, n (\%) & $125(20.4)$ \\
\hline Stage 1 elephant trunk & $\begin{array}{c}85(68.0 \% \text { of total arch } \\
\text { replacement })\end{array}$ \\
\hline $\begin{array}{l}\text { Distal arch anastomosis } \\
\text { proximal to left subclavian } \\
\text { artery }\end{array}$ & $\begin{array}{c}94(75.2 \% \text { of total arch } \\
\text { replacement })\end{array}$ \\
\hline $\begin{array}{l}\text { Distal arch anastomosis } \\
\text { proximal to carotid }\end{array}$ & $\begin{array}{c}5(5.3 \% \text { of total arch } \\
\text { replacement })\end{array}$ \\
\hline $\begin{array}{l}\text { Individual branch } \\
\text { reimplantation }\end{array}$ & $\begin{array}{c}49(39.2 \% \text { of total arch } \\
\text { replacement })\end{array}$ \\
\hline $\begin{array}{l}\text { Extra-anatomic subclavian artery } \\
\text { bypass graft, } \mathrm{n}(\%)\end{array}$ & $\begin{array}{l}8(1.3) ; 2(0.3) \text { during } \\
\text { follow-up }\end{array}$ \\
\hline $\begin{array}{l}\text { Coronary artery bypass graft, } \\
\mathrm{n}(\%)\end{array}$ & $86(14.0)$ \\
\hline Mitral valve surgery, n (\%) & $4(0.7)$ \\
\hline Intra-aortic balloon pump, n (\%) & $7(1.1)$ \\
\hline $\begin{array}{l}\text { Left ventricular assist device, } \\
\text { n }(\%)\end{array}$ & $2(0.3)$ \\
\hline $\begin{array}{l}\text { Circulatory arrest time, min, } \\
\text { mean } \pm \text { SD range })\end{array}$ & $29.7 \pm 8.5(10-62)$ \\
\hline In hemiarch replacements & $26.6 \pm 5.4(10-50)$ \\
\hline In arch replacements & $41.0 \pm 7.5(22-61)$ \\
\hline $\begin{array}{l}\text { Cross-clamp time, } \min \\
\text { mean } \pm \text { SD }(\text { range })(n=590)\end{array}$ & $88.5 \pm 28.1(30-176)$ \\
\hline $\begin{array}{l}\text { Cardiopulmonary bypass time, } \\
\text { min, mean } \pm \text { SD (range) } \\
(\mathrm{n}=610)\end{array}$ & $157.5 \pm 34.3(82-349)$ \\
\hline $\begin{array}{l}\text { Reintervention during } \\
\text { follow-up, } \mathrm{n}\end{array}$ & 56 \\
\hline Cardiac surgery & 4 \\
\hline Proximal aortic reoperation & 6 \\
\hline Distal aortic reintervention & 48 \\
\hline Open distal reoperation & 46 \\
\hline $\begin{array}{l}\text { Stage } 2 \text { elephant trunk } \\
\text { completion }\end{array}$ & 38 \\
\hline $\begin{array}{l}\text { Endovascular distal } \\
\text { reintervention }\end{array}$ & 5 \\
\hline
\end{tabular}

$S D$, Standard deviation.

95\% CI, 0.93-1.65). Survival curves are shown in Figures 1 and 2.

Patients with an aneurysm had better 1- and 5- year survival rates than those undergoing surgery for dissection
TABLE 3. Early postoperative mortality and morbidity $(n=613)$

\begin{tabular}{|c|c|}
\hline Variable & Value \\
\hline $\begin{array}{l}\text { Operative mortality (including in-hospital } \\
\text { mortality and 30-d mortality) } \\
(\mathrm{n}=597), \mathrm{n}(\%)\end{array}$ & $18(2.9)$ \\
\hline Elective cases $(\mathrm{n}=529)$ & $8(1.5)$ \\
\hline $\begin{array}{l}\text { Elective, nondissection, first-time cases } \\
\qquad(\mathrm{n}=424)(\mathrm{n}=411)\end{array}$ & $4(0.9)$ \\
\hline $\begin{array}{l}\text { Elective, nondissection, first-time, } \\
\text { age }<60 \text { y }(\mathrm{n}=148)\end{array}$ & $0(0)$ \\
\hline Reexploration for bleeding, $\mathrm{n}(\%)$ & $33(5.4)$ \\
\hline $\begin{array}{l}\text { Pulmonary complication (pneumonia, } \\
\text { pleural effusion, pneumothorax), } \mathrm{n}(\%)\end{array}$ & $33(5.3)$ \\
\hline Postoperative ventilation exceeding $48 \mathrm{~h}, \mathrm{n}(\%)$ & $29(4.7)$ \\
\hline Tracheostomy, n (\%) & $3(0.5)$ \\
\hline Atrial fibrillation, $\mathrm{n}(\%)$ & $270(44)$ \\
\hline Renal replacement therapy, n (\%) & $7(1.1)$ \\
\hline Stroke, n (\%) & $12(2)$ \\
\hline Seizure, n (\%) & $6(1)$ \\
\hline Temporary neurologic deficit, n (\%) & $31(5.1)$ \\
\hline Pericardial effusion (requiring drainage), $\mathrm{n}(\%)$ & $11(1.8)$ \\
\hline $\begin{array}{l}\text { Wound complication (requiring debridement), } \\
\mathrm{n}(\%)\end{array}$ & $12(2)$ \\
\hline Pacemaker implantation, $\mathrm{n}(\%)$ & $8(1.3)$ \\
\hline $\begin{array}{l}\text { Intensive care unit stay, } d \text {, mean } \pm S D \\
\quad(\text { range })(n=593)\end{array}$ & $3.64 \pm 5.2(0-85)$ \\
\hline Hospital stay, $d$, mean \pm SD (range) $(n=604)$ & $7.32 \pm 7.0(0-87)$ \\
\hline
\end{tabular}

$S D$, Standard deviation.

(94.7\% and $84.1 \%$ vs $75.4 \%$ and $64.3 \%$, respectively; $P=.000)$. In patients with an initial extension of aortic pathology into the descending aorta, 1- and 5- year survival rates were $79.8 \%$ and $64.7 \%$, respectively. Patients undergoing hemiarch replacement had significantly better survival than those undergoing arch replacement $(94.9 \%$ at 1 year and $85.5 \%$ at 5 years vs $83.3 \%$ and $66.0 \%$, respectively; $P=.000$ ).

\section{Factors Associated With Mortality Within the First Postoperative Year}

The strongest univariable factors associated with mortality within the first year were descending aortic pathology (defined as an aortic pathology that includes the descending thoracic aorta; HR, 5.54; 95\% CI, 3.02-10.16; $P=.000$ ), aortic dissection (HR, 5.80; 95\% CI, 3.02-10.13; $P=.000$ ), acute type A aortic dissection (ATAAD) (HR, 4.84; 95\% CI, 2.33-10.08; $P=.000$ ), redo surgery (HR, $4.12 ; 95 \% \mathrm{CI}, 2.27-7.48 ; P=.000)$, and urgent/emergent surgery (HR, 3.72; 95\% CI, 1.99-6.94; $P=.000$ ). The presence of postoperative complications also was strongly associated with poor 1 year-survival. The results of univariable Cox regression analysis are presented in Table E1. 


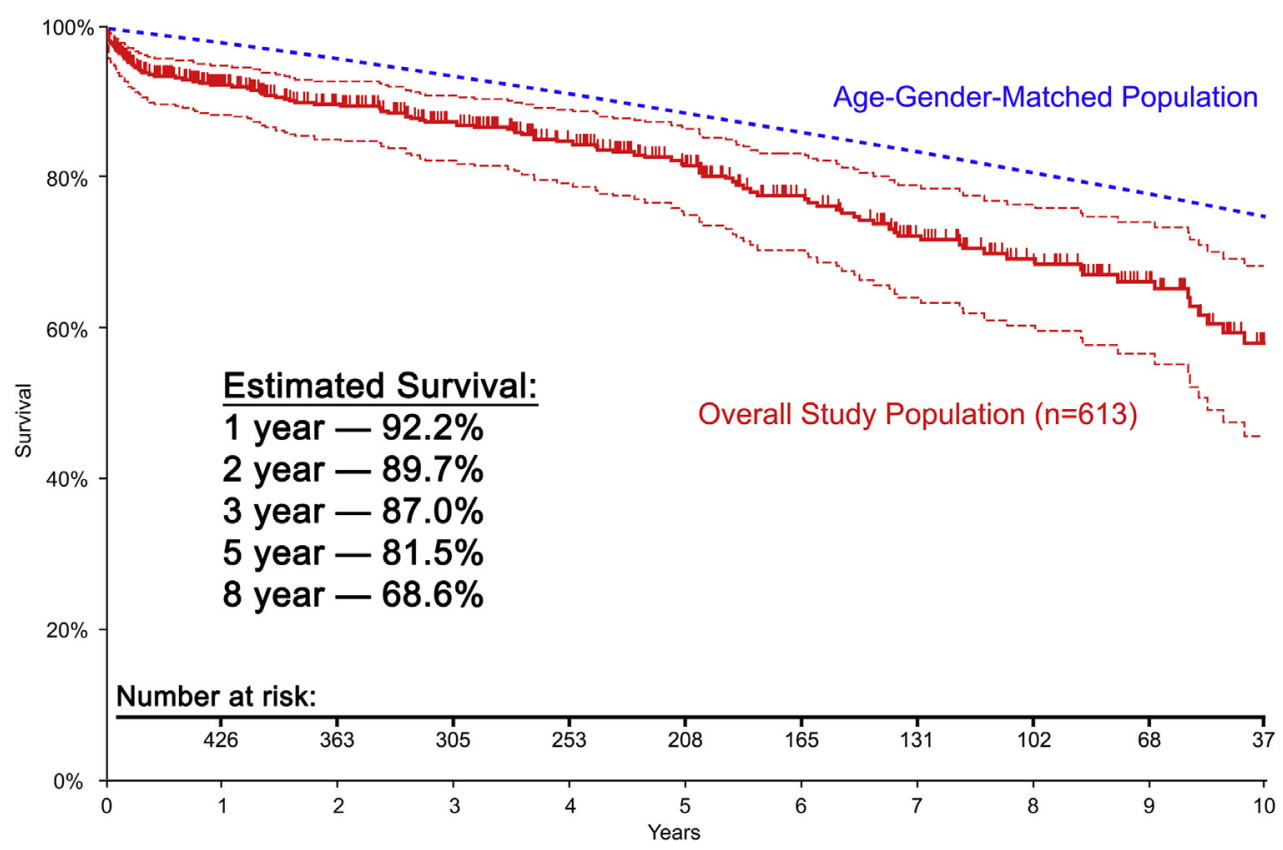

FIGURE 1. Kaplan-Meier survival compared with a reference population $(\mathrm{n}=613)$ : overall study group. Rug marks represent censored patients; dotted lines represent confidence bands. The survival of the DHCA patients is significantly different (lower) than that of the age- and sex-matched population.

Four variables could be fitted into a multivariable model to avoid overfitting. ATAAD (HR, 3.78; 95\% CI, 1.66-8.77; $P=.002$ ), redo status (HR, 3.63; 95\% CI, 1.86-7.10; $P=.000)$, and descending aortic pathology (HR, 2.60; $95 \%$ CI, 1.02-5.72; $P=.018$ ) were identified as independently associated with 1-year mortality. DHCA time was not independently associated with 1-year mortality $(P=.197)$. The results of multivariable Cox regression analysis for 1-year survival are presented in Table 4. Before adjustment, the duration of DHCA had an influence on survival, but after multivariable adjustment, this influence was no longer significant.

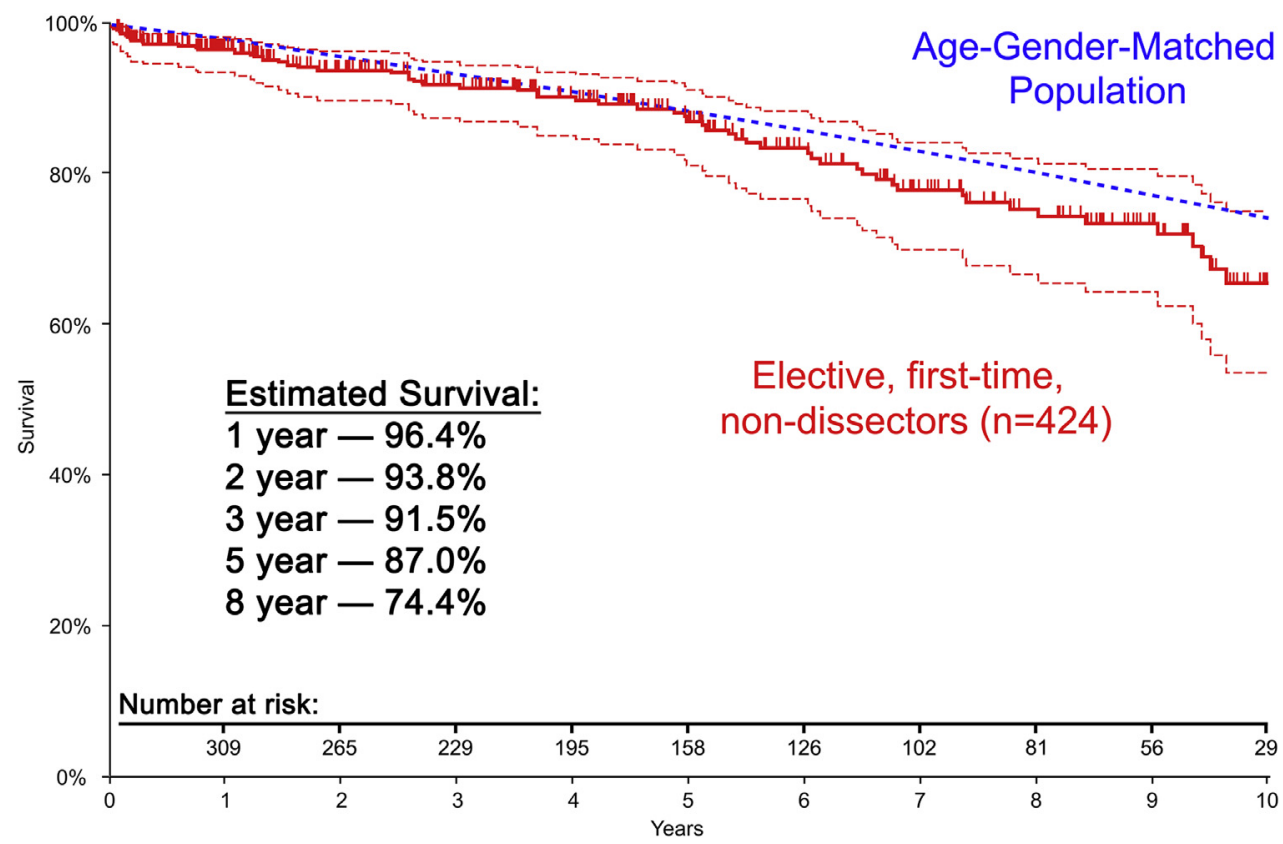

FIGURE 2. Kaplan-Meier survival compared with a reference population $(n=424)$ : elective, first-time nondissection cases. Rug marks represent censored patients; dotted lines represent confidence bands. The survival of this group of DHCA patients is not significantly different from the age- and sex-matched population. 
TABLE 4. Multivariable Cox proportional hazards regression analysis

\begin{tabular}{|c|c|c|}
\hline Variable & HR, mean SD $(95 \%$ CI $)$ & $P$ value \\
\hline \multicolumn{3}{|l|}{ Early survival $(1 \mathrm{y})(\mathrm{n}=613$ patients; $\mathrm{n}=43$ events during follow-up $)$} \\
\hline \multicolumn{3}{|l|}{ Significantly associated variables } \\
\hline Acute type A aortic dissection & $3.78 \pm 0.43(1.66-8.77)$ & .002 \\
\hline Redo status & $3.63 \pm 0.34(1.86-7.10)$ & .000 \\
\hline Descending extension of aortic pathology & $2.60 \pm 0.40(1.02-5.724)$ & .018 \\
\hline \multicolumn{3}{|l|}{ Nonsignificantly associated variables } \\
\hline Circulatory arrest time & $1.02 \pm 0.02(0.99-1.06)$ & .197 \\
\hline \multicolumn{3}{|l|}{ Late survival (beyond 1 y) $(n=4161$-year survivors; $n=77$ events during follow-up) } \\
\hline \multicolumn{3}{|l|}{ Significantly associated variables } \\
\hline Age & $1.06 \pm 0.01(1.03-1.08)$ & .000 \\
\hline Postoperative major complication (stroke, renal replacement therapy, pulmonary complication) & $2.40 \pm 0.24(1.48-3.86)$ & .000 \\
\hline Postoperative atrial fibrillation (occurring within $30 \mathrm{~d} /$ during hospital stay) & $1.76 \pm 0.26(1.06-2.90)$ & .028 \\
\hline \multicolumn{3}{|l|}{ Nonsignificantly associated variables } \\
\hline Circulatory arrest time & $1.01 \pm 0.02(0.98-1.05)$ & .371 \\
\hline Acute type A dissection & $2.26 \pm 0.42(0.99-5.18)$ & .053 \\
\hline Descending extension of aortic pathology & $1.40 \pm 0.33(0.74-2.66)$ & .303 \\
\hline Coronary artery disease & $1.24 \pm 0.27(0.73-2.08)$ & .428 \\
\hline
\end{tabular}

$H R$, Hazard ratio; $S D$, standard deviation; $C I$, confidence interval.

\section{Factors Associated With Mortality Beyond 1 Year}

Among 419 patients who survived and were observed beyond 1 year, the strongest univariable factor associated with poor survival were age (HR, $1.07 ; 95 \% \mathrm{CI}$, $1.05-1.10$ per 1 -year increase; $P=.000$ ), ATAAD (HR, 2.33; 95\% CI, 1.07-5.09; $P=.034$ ), and postoperative complications. The results of univariable Cox regression analysis are presented in Table E2.

In multivariable Cox regression analysis, age (HR, 1.06; 95\% CI, 1.03-1.08 per 1-year increase; $P=.000$ ), postoperative atrial fibrillation (HR, 1.76; 95\% CI, 1.06-2.90; $P=.028$ ), and a combined variable comprising postoperative complications of stroke, renal replacement therapy, and pulmonary complications (HR, 2.40; 95\% CI, 1.48-3.86; $P=.000$ ) were identified as independently associated with poor survival. The combined ordinal variable of stroke, dialysis, and pulmonary complications was constructed because these 3 variables emerged as the strongest univariable covariates and had a high degree of correlation. In multivariable analysis, descending extension of aortic pathology and DHCA duration did not emerge as factors independently associated with late mortality; neither did ATAAD, although a trend was apparent $(P=.371)$. The results of multivariable Cox regression analysis for survival beyond 1 year are presented in Table 4.

\section{Reinterventions During Follow-up}

During follow-up, 56 of 595 hospital survivors underwent cardiac or aortic reintervention. Among the patients undergoing reintervention, 30-day mortality was $10.7 \%$. Six patients underwent proximal aortic reoperation. Five of the 36 patients with ATAAD underwent reintervention.
Distal aortic reintervention was performed in 48 patients. This consisted of open descending aortic replacement in 46 (including 38 stage 2 elephant trunk completions) and endovascular procedures of the thoracoabdominal aorta in 5 patients, with several patients undergoing multiple distal reinterventions. The cumulative incidence of reintervention in a semiparametric competing-risks model with interim death as the competing risk was significantly higher in the patients with descending extension of aortic pathology at initial surgery (Figure 3).

\section{DISCUSSION}

Early postoperative results with regard to mortality, stroke, and other postoperative complications were encouraging and consistent with our group's previous studies as well as with similar publications on aortic arch replacement. ${ }^{1,5,13}$ Operative mortality was very low, especially in low-risk patients. Overall Kaplan-Meier survival analysis estimated 1-, 5-, and 8-year survival of $92.2 \%, 81.5 \%$, and $68.6 \%$. These findings are within the previously published ranges of survival estimates for aortic (arch) surgery of $63 \%$ to $82 \%$ at 5 years and $53 \%$ to $78 \%$ at 10 years. ${ }^{14-19}$ These results demonstrate that aortic arch surgery using straight DHCA is safe and can match other techniques in terms of early and late outcomes.

Our study cohort had significantly worse survival compared with the reference population, in agreement with previous reports. ${ }^{2,19,20}$ However, after exclusion of high-risk patients who underwent emergency surgery, surgery for aortic dissection, or redo surgery, a negative effect on late survival was no longer apparent. These data show that in low-risk patients, aortic arch surgery can indeed achieve normal life expectancy. 


\section{Cumulative Incidence for Re-Intervention} (Competing-Risks)

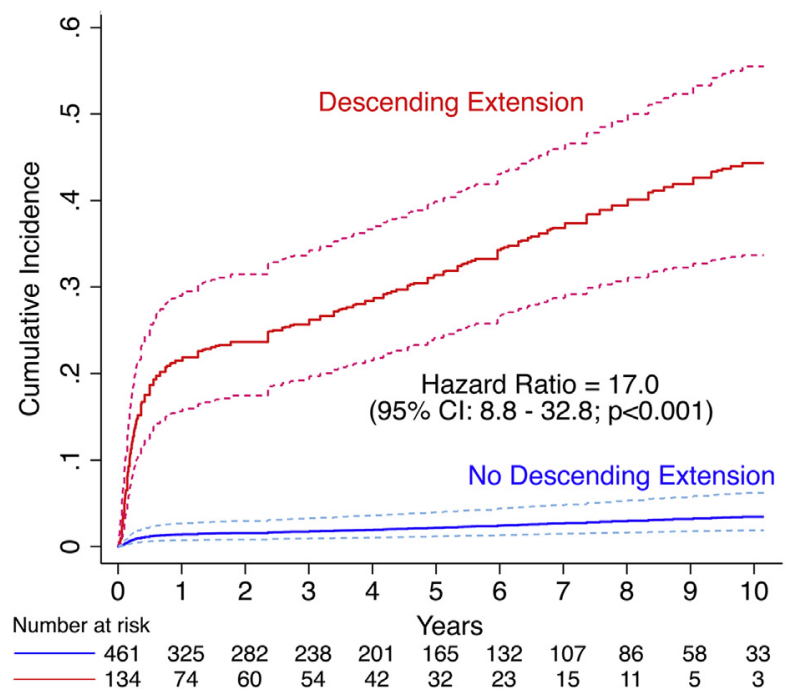

FIGURE 3. Cumulative incidence of reintervention depending on initial presence of descending extension of aortic pathology ( $n=595$ hospital survivors, semiparametric competing-risks model with interim death as competing risk). Dotted lines represent confidence bands. CI, Confidence Interval.

Factors associated with survival differed between the early postoperative phase and survival beyond 1 year. One-year survival was negatively influenced mainly by ATAAD, perioperative risk factors, and descending extension of aortic pathology. Beyond 1 year, age, major postoperative complications, and postoperative atrial fibrillation were identified as independently associated with reduced late survival.

It is well known that ATAAD carries a high risk of operative mortality and stroke. ${ }^{21-23}$ Pape et $\mathrm{al}^{22}$ of the International Registry of Aortic Dissection reported a surgical mortality of $18 \%$ in the registry in recent years. The estimated 1-year survival of only $74 \%$ in our analysis is compatible with previously reported findings, keeping in mind that we did not exclude hospital mortality from our analysis. ${ }^{15,19,23-28}$ These results support the need for timely diagnosis and elective surgery in patients with an elevated risk of aortic rupture or dissection. Given that elective operative mortality is relatively low and aortic dissection is strongly associated with poor outcomes, we tend to intervene electively at smaller sizes in patients at risk. In our series, the average ascending aortic size for elective interventions was $5.2 \mathrm{~cm}$, and the average ASI was $2.69 \mathrm{~cm} / \mathrm{m}^{2}{ }^{6,29}$ Complications concerning the unreplaced remaining aorta could potentially limit late survival in these patients. ${ }^{23,26}$ In this study group, 5 of 36 patients with acute aortic dissection underwent reintervention.

Reoperation was the variable with the second-strongest association with poor early survival. Patients undergoing reoperative surgery had a higher rate of perioperative adverse events, as reported previously. ${ }^{20,30}$ Most patients undergoing redo surgery presented with aneurysmal progression. The increased risk of reoperative surgery on the aortic arch underlines the importance of initially considering a more distal extent of resection at the first operation. . $^{0,30,31}$

Patients with descending extension of aortic pathology had significantly worse survival in the first year, but no significant difference in late survival. Almost half $(45.1 \%)$ of these patients had dissection. These patients were more likely to undergo total arch replacement $(69.4 \%)$, often including an elephant trunk for a stage 2 descending intervention (59\%). These factors could account in part for the higher early mortality. ${ }^{14,19,24}$

A crucial factor in late survival of patients with pathology of the descending aorta is the presence of distal aortic complications and operations. ${ }^{16-18,23,25,26,32}$ The cumulative incidence of reintervention was significantly higher among patients with descending extension of aortic pathology. Overall, 48 patients underwent mainly open surgical secondary distal intervention. Many of these were planned stage 2 elephant trunk procedures, most performed within 1 year of primary surgery. Therefore, the steepest increase in the cumulative incidence of reintervention among patients with descending aortic pathology is seen within the first year (Figure 3). Reported rates of secondary distal intervention rates are similar, varying widely depending on aortic pathologies. ${ }^{17-19,23,25,26,32}$ Descending aortic pathology was associated with reduced survival only in the early postoperative period, possibly due in part to stage 2 elephant trunk procedures. After 1 year, descending pathology no longer affected survival. These findings indicate that with appropriate interventions and close observation, the impact of descending aortic pathology on late survival can be limited; however, good operative results, especially in major open downstream procedures, are crucial for these patients.

Only 6 of 595 hospital survivors underwent proximal aortic reintervention during follow-up. This finding compares very favorably with data in the literature. $^{14,16,17,19,32}$ Although freedom of reintervention does not equal disease-free survival, these data suggest that the less extensive approach to the aortic arch, via a 2 -vessel patch reimplantation of the head vessels using straight DHCA, does not come at the expense of higher late reoperation rates.

Not surprisingly, major postoperative complications had strong adverse effects on survival. Interestingly, postoperative atrial fibrillation remained an independent risk factor even after multivariable adjustment. Importantly, the management of atrial fibrillation in these patients was unknown. The occurrence of postoperative atrial fibrillation 
is generally considered benign, but it has been associated with poor late survival. ${ }^{33}$ Whether atrial fibrillation is directly causative of increased mortality or is a surrogate for a poorer health state is unclear, ${ }^{33}$ but these results suggest that the significance of postoperative atrial fibrillation should not be underestimated.

To our knowledge, this is the largest study on late survival after aortic surgery with straight DHCA published to date. Large comparative studies of late survival with different cerebral protection techniques are particularly rare. Results so far have been mixed, with Wiedemann et $\mathrm{al}^{28}$ identifying nonuse of antegrade cerebral perfusion as a risk factor for poor late survival in ATAAD but others, including the largest study reported by Misfeld et $\mathrm{al},{ }^{15}$ finding no association between perfusion technique and late survival after aortic arch surgery. ${ }^{24,34}$ Patel et $\mathrm{al}^{14}$ identified prolonged circulatory arrest times (using different cerebral protection techniques) as independently associated with late mortality. In contrast, in the present study, DHCA time as a continuous variable was not independently associated with poor survival in multivariable analysis neither within nor beyond 1 year. The significance of DHCA time in univariable analysis might be due to the associations between this variable and procedural complexity and extent, and it loses its significance when adjusted for these factors. The finding of no significant association between DHCA time and late survival suggests that the supposed subtle brain damage possibly caused by DHCA, which might not be detected using hard data, is limited or at least has only a limited effect on late survival. ${ }^{1,4,35}$ However, this result should not be interpreted to mean that straight DHCA can be used safely for unlimited periods, given that very few patients had a DHCA time $>50$ minutes, and thus this analysis has less validity for DHCA times at the extreme end.

\section{Study Limitations}

This study has several limitations, related mainly to its retrospective design. Several risk factors could not be studied in detail, including temporary neurologic deficit or management of atrial fibrillation, hypertension, and coronary artery disease. This study did not include neuropsychological and neurologic testing, so only clinically apparent neurologic injury could be accounted for. Our group has investigated quantitative neurologic outcomes in previous studies. ${ }^{36}$ Causes of death were unknown for most patients, precluding analysis. Concerning reinterventions, only procedures at Yale-New Haven Hospital could be accounted for, potentially leading to unreported reinterventions. Statistical power, particularly regarding subgroups, was limited by their smaller size and the rarity of certain variables and events. Breaking up survival analysis in 2 time periods because of nonproportional hazards might decrease power further. ${ }^{11}$
Finally, our cohort represents a single-center and single-surgeon experience, limiting its generalizability.

\section{CONCLUSIONS}

Aortic arch surgery with straight DHCA can be performed with favorable late survival. In low-risk patients, arch surgery can even achieve normal life expectancy. The duration of DHCA does not have a statistically significant independent influence on late survival. We acknowledge that these results cannot be generalized for very long DHCA times ( $>50$ minutes), when perfusion methods may be preferable. Early survival is impaired mainly by the presence of acute type A dissection, redo surgery, greater extent of aortic pathology, and general risk factors, whereas the factors most strongly associated with poor late survival are age and postoperative complications.

\section{Conflict of Interest Statement}

Authors have nothing to disclose with regard to commercial support.

\section{References}

1. Tian DH, Wan B, Bannon PG, Misfeld M, LeMaire SA, Kazui T, et al. A meta-analysis of deep hypothermic circulatory arrest alone versus with adjunctive selective antegrade cerebral perfusion. Ann Cardiothorac Surg. 2013;2:261-70

2. Bischoff MS, Brenner RM, Scheumann J, Bodian CA, Griepp RB, Lansman SL, et al. Long-term outcome after aortic arch replacement with a trifurcated graft. $J$ Thorac Cardiovasc Surg. 2010;140(6 Suppl):S71-6; discussion S86-91.

3. Tian DH, Wan B, Bannon PG, Misfeld M, LeMaire SA, Kazui T, et al. A meta-analysis of deep hypothermic circulatory arrest versus moderate hypothermic circulatory arrest with selective antegrade cerebral perfusion. Ann Cardiothorac Surg. 2013;2:148-58.

4. Fleck TM, Czerny M, Hutschala D, Koinig H, Wolner E, Grabenwoger M. The incidence of transient neurologic dysfunction after ascending aortic replacement with circulatory arrest. Ann Thorac Surg. 2003;76:1198-202.

5. Ziganshin BA, Rajbanshi BG, Tranquilli M, Fang H, Rizzo JA, Elefteriades JA. Straight deep hypothermic circulatory arrest for cerebral protection during aortic arch surgery: safe and effective. J Thorac Cardiovasc Surg. 2014;148:888-98; discussion 898-900.

6. Davies RR, Gallo A, Coady MA, Tellides G, Botta DM, Burke B, et al. Novel measurement of relative aortic size predicts rupture of thoracic aortic aneurysms. Ann Thorac Surg. 2006;81:169-77.

7. Peterss S, Charilaou P, Ziganshin BA, Elefteriades JA. Assessment of survival in retrospective studies: The Social Security Death Index is not adequate for estimation. J Thorac Cardiovasc Surg. 2017;153:899-901.

8. Arias E. US Department of Health and Human Services, Division of Vital Statistics. United States life tables, 2006. Natl Vital Stat Rep. 2010;58:1-40.

9. Arias E. US Department of Health and Human Services, Division of Vital Statistics. United States life tables, 2007. Natl Vital Stat Rep. 2011;59:1-60.

10. Finkelstein DM, Muzikansky A, Schoenfeld DA. Comparing survival of a sample to that of a standard population. J Natl Cancer Inst. 2003;95:1434-9.

11. Bellera CA, MacGrogan G, Debled M, de Lara CT, Brouste V, MathoulinPélissier S. Variables with time-varying effects and the Cox model: some statistical concepts illustrated with a prognostic factor study in breast cancer. BMC Med Res Methodol. 2010;10:20.

12. Rizzo JA, Chen J, Fang H, Ziganshin BA, Elefteriades JA. Statistical challenges in identifying risk factors for aortic disease. Aorta (Stamford). 2014;2:45-55.

13. Chau KH, Ziganshin BA, Elefteriades JA. Deep hypothermic circulatory arrest: real-life suspended animation. Prog Cardiovasc Dis. 2013;56:81-91.

14. Patel HJ, Nguyen C, Diener AC, Passow MC, Salata D, Deeb GM. Open arch reconstruction in the endovascular era: analysis of 721 patients over 17 years. J Thorac Cardiovasc Surg. 2011;141:1417-23. 
15. Misfeld M, Leontyev S, Borger MA, Gindensperger O, Lehmann S, Legare JF, et al. What is the best strategy for brain protection in patients undergoing aortic arch surgery? A single center experience of 636 patients. Ann Thorac Surg. 2012; 93:1502-8.

16. Di Eusanio M, Berretta P, Cefarelli M, Castrovinci S, Folesani G, Alfonsi J, et al. Long-term outcomes after aortic arch surgery: results of a study involving 623 patients. Eur J Cardiothorac Surg. 2015;48:483-90.

17. Iba Y, Minatoya K, Matsuda H, Sasaki H, Tanaka H, Kobayashi J, et al. Contemporary open aortic arch repair with selective cerebral perfusion in the era of endovascular aortic repair. J Thorac Cardiovasc Surg. 2013;145(3 Supp1):S72-7.

18. Okita Y, Okada K, Omura A, Kano H, Minami H, Inoue T, et al. Total arch replacement using antegrade cerebral perfusion. J Thorac Cardiovasc Surg. 2013;145(3 Suppl):S63-71.

19. Bekkers JA, te Riele RJ, Takkenberg JJ, Bol Raap G, Hofland J, Roos-Hesselink JW, et al. Thoracic aortic surgery: an overview of 40 years clinical practice. $J$ Thorac Cardiovasc Surg. 2014;147:332-43.

20. Etz CD, Plestis KA, Homann TM, Bodian CA, Di Luozzo G, Spielvogel D, et al. Reoperative aortic root and transverse arch procedures: a comparison with contemporaneous primary operations. J Thorac Cardiovasc Surg. 2008;136: 860-7. 867.e1-3.

21. Czerny M, Schoenhoff F, Etz C, Englberger L, Khaladj N, Zierer A, et al. The impact of pre-operative malperfusion on outcome in acute type A aortic dissection: results from the GERAADA registry. J Am Coll Cardiol. 2015;65: 2628-35.

22. Pape LA, Awais M, Woznicki EM, Suzuki T, Trimarchi S, Evangelista A, et al. Presentation, diagnosis, and outcomes of acute aortic dissection: 17-year trends from the International Registry of Acute Aortic Dissection. J Am Coll Cardiol. 2015;66:350-8.

23. Omura A, Miyahara S, Yamanaka K, Sakamoto T, Matsumori M, Okada K, et al. Early and late outcomes of repaired acute DeBakey type I aortic dissection after graft replacement. J Thorac Cardiovasc Surg. 2016;151: 341-8.

24. Estrera AL, Miller CC III, Huynh TT, Porat EE, Safi HJ. Replacement of the ascending and transverse aortic arch: determinants of long-term survival. Ann Thorac Surg. 2002;74:1058-64; discussion 1064-5.

25. Di Eusanio M, Berretta P, Cefarelli M, Jacopo A, Murana G, Castrovinci S, et al. Total arch replacement versus more conservative management in type A acute aortic dissection. Ann Thorac Surg. 2015;100:88-94.
26. Rylski B, Milewski RK, Bavaria JE, Vallabhajosyula P, Moser W, Szeto WY et al. Long-term results of aggressive hemiarch replacement in 534 patients with type A aortic dissection. J Thorac Cardiovasc Surg. 2014;148:2981-5.

27. Tsai TT, Evangelista A, Nienaber CA, Trimarchi S, Sechtem U, Fattori R, et al Long-term survival in patients presenting with type A acute aortic dissection: insights from the International Registry of Acute Aortic Dissection (IRAD) Circulation. 2006;114(1 Suppl):I350-6.

28. Wiedemann D, Kocher A, Dorfmeister M, Vadehra A, Mahr S, Laufer G, et al Effect of cerebral protection strategy on outcome of patients with Stanford type A aortic dissection. J Thorac Cardiovasc Surg. 2013;146:647-55.e1.

29. Ziganshin BA, Elefteriades JA. Treatment of thoracic aortic aneurysm: role of earlier intervention. Semin Thorac Cardiovasc Surg. 2015;27:135-43.

30. Di Bartolomeo R, Berretta P, Petridis FD, Folesani G, Cefarelli M, Di Marco L, et al. Reoperative surgery on the thoracic aorta. J Thorac Cardiovasc Surg. 2013; 145(3 Suppl):S78-84.

31. Czerny M, Barchichat I, Meszaros K, Sodeck GH, Weber A, Reineke D, et al Long-term results after proximal thoracic aortic redo surgery. PLoS One. 2013 8:e57713.

32. Concistrè G, Casali G, Santaniello E, Montalto A, Fiorani B, Dell' Aquila A, et al Reoperation after surgical correction of acute type A aortic dissection: risk factor analysis. Ann Thorac Surg. 2012;93:450-5.

33. Phan K, Ha HS, Phan S, Medi C, Thomas SP, Yan TD. New-onset atrial fibrillation following coronary bypass surgery predicts long-term mortality: a systematic review and meta-analysis. Eur J Cardiothorac Surg. 2015;48:817-24.

34. Kaneko T, Aranki SF, Neely RC, Yazdchi F, McGurk S, Leacche M, et al. Is there a need for adjunct cerebral protection in conjunction with deep hypothermic circulatory arrest during noncomplex hemiarch surgery? J Thorac Cardiovasc Surg. 2014;148:2911-7.

35. Krahenbuhl ES, Immer FF, Stalder M, Englberger L, Eckstein FS, Carrel TP Temporary neurological dysfunction after surgery of the thoracic aorta: a predictor of poor outcome and impaired quality of life. Eur J Cardiothorac Surg. 2008;33:1025-9.

36. Chau KH, Friedman T, Tranquilli M, Elefteriades JA. Deep hypothermic circulatory arrest effectively preserves neurocognitive function. Ann Thorac Surg. 2013;96:1553-9.

Key Words: aortic surgery, aortic arch replacement, cerebral protection 
TABLE E1. Univariable Cox proportional hazard regression for 1-year survival $(\mathbf{n}=613)$

\begin{tabular}{lcc}
\hline \multicolumn{1}{c}{ Variable } & $\begin{array}{c}\text { HR, mean } \pm \text { SD } \\
(\mathbf{9 5} \% \mathbf{C I})\end{array}$ & $\begin{array}{c}\boldsymbol{P} \\
\text { value }\end{array}$ \\
\hline Comorbidities & & \\
Chronic renal failure & $2.15 \pm 0.39(0.998-4.621)$ & .051 \\
Coronary artery disease & $2.24 \pm 0.31(1.21-4.13)$ & .010 \\
Redo status & $4.12 \pm 0.31(2.27-7.48)$ & .000 \\
Aortic pathology & & \\
Urgent or emergent surgery & $3.72 \pm 0.32(1.99-6.94)$ & .000 \\
Acute type A aortic dissection & $4.84 \pm 0.37(2.33-10.08)$ & .000 \\
Aortic aneurysm & $0.21 \pm 0.30(0.12-0.39)$ & .000 \\
Aortic dissection & $5.80 \pm 0.30(3.08-10.13)$ & .000 \\
Descending extension & $5.54 \pm 0.31(3.02-10.16)$ & .000 \\
$\quad$ of aortic disease & & \\
Surgical variables & & \\
Hemiarch replacement & $0.31 \pm 0.30(0.17-0.57)$ & .000 \\
Total arch replacement & $3.02 \pm 0.30(1.66-5.48)$ & .000 \\
Circulatory arrest time & $1.08 \pm 0.01(1.05-1.11)$ & .000 \\
Cardiopulmonary bypass & $1.02 \pm 0.00(1.01-1.03)$ & .000 \\
$\quad$ time (n = 611) & & \\
Postoperative complications & & \\
Pulmonary complication & $5.64 \pm 0.36(2.78-11.41)$ & .000 \\
Renal replacement therapy & $11.66 \pm 0.53(4.16-32.67)$ & .000 \\
Reexploration for bleeding & $9.08 \pm 0.33(4.75-17.37)$ & .000 \\
Postoperative atrial fibrillation & $2.26 \pm 0.31(1.22-4.17)$ & .009 \\
Stroke & $17.05 \pm 0.39(7.90-36.83)$ & .000 \\
\hline
\end{tabular}

Nonsignificant predictors included sex, age, history of smoking, chronic obstructive pulmonary disease, arterial hypertension, central nervous system comorbidity, diabetes mellitus, dyslipidemia, atrial fibrillation, aortic valve replacement, aortic root replacement, root-sparing procedure, coronary artery bypass graft, cross-clamp time, temporary neurologic deficit, seizure, and wound complications. $H R$, Hazard ratio; $S D$, standard deviation; $C I$, confidence interval.
TABLE E2. Univariable Cox proportional hazard regression for survival beyond 1 year $(n=419$ alive and not censored at 1 year $)$

\begin{tabular}{lcc}
\hline \multicolumn{1}{c}{ Variable } & HR, mean \pm SD (95\% CI) & $\begin{array}{c}\boldsymbol{P} \\
\text { value }\end{array}$ \\
\hline $\begin{array}{l}\text { Demographic variable } \\
\quad \text { Age }\end{array}$ & $1.07 \pm 0.01(1.05-1.10)$ & .000 \\
Comorbidities & $2.06 \pm 0.30(1.16-3.69)$ & .014 \\
$\quad$ Arterial hypertension & $1.65 \pm 0.23(1.05-2.59)$ & .030 \\
Dyslipidemia & $2.47 \pm 0.33(1.30-4.69)$ & .006 \\
Atrial fibrillation & $2.01 \pm 0.25(1.23-3.28)$ & .005 \\
Coronary artery disease & & \\
Aortic pathology & & \\
Acute type A aortic dissection & $2.33 \pm 0.40(1.07-5.09)$ & .034 \\
Aortic aneurysm & $0.52 \pm 0.30(0.29-0.93)$ & .028 \\
Descending extension & $1.74 \pm 0.27(1.02-2.97)$ & .042 \\
$\quad$ of aortic disease & & \\
Surgical variables & & \\
Aortic root replacement & $0.43 \pm 0.30(0.24-0.79)$ & .006 \\
Root-sparing procedure & $2.29 \pm 0.30(1.27-4.10)$ & .006 \\
Coronary artery bypass graft & $2.10 \pm 0.26(1.27-3.51)$ & .004 \\
Circulatory arrest time & $1.05 \pm 0.01(1.02-1.08)$ & .000 \\
\hline Postoperative complications & & \\
Pulmonary complication & $4.31 \pm 0.36(2.13-8.73)$ & .000 \\
Renal replacement therapy & $13.16 \pm 0.73(3.15-55.00)$ & .000 \\
Postoperative atrial fibrillation & $2.55 \pm 0.24(1.60-4.06)$ & .000 \\
Temporary neurologic deficit & $2.36 \pm 0.43(1.02-5.42)$ & .044 \\
Stroke & $7.82 \pm 1.03(1.05-58.26)$ & .045 \\
\hline
\end{tabular}

Nonsignificant predictors included sex, chronic obstructive pulmonary disease, central nervous system comorbidity, diabetes mellitus, chronic renal failure, redo status, urgent or emergent surgery, aortic dissection, aortic valve replacement, hemiarch replacement, total arch replacement, cross-clamp time, cardiopulmonary bypass time, reexploration for bleeding, seizure, and wound complications. $H R$, Hazard ratio; $S D$, standard deviation; $C I$, confidence interval. 